\title{
EFFECT OF COMBINED ORAL FERROTHERAPY WITH L-CARNITINE ON EXERCISE TOLERANCE OF PATIENTS WITH CHRONIC HEART FAILURE WITH REDUCED EJECTION FRACTION OF LEFT VENTRICLE WITH CONCOMITANT IRON DEFICIENCY ANEMIA
}

\author{
Valerii Ivanov ${ }^{l}$ \\ ivanov.vp1965@gmail.com \\ Mariia Kolesny $\boldsymbol{k}^{1}$ \\ mokolesnyk@gmail.com \\ ${ }^{1}$ Department of internal medicine No. 3 \\ National Pirogov Memorial Medical University, Vinnytsya \\ 56 Pirogova str., Vinnytsya, Ukraine, 21018
}

\begin{abstract}
According to numerous studies, a high prevalence of iron deficiency (ID) with anaemic syndrome and its association with mortality during chronic heart failure (CHF) have been revealed. Ferrocorrection of anaemia during CHF is important both to improve the clinical condition and to optimize the long-term prognosis of patients. However, the pathogenetic justification is the use of agents that have antihypoxic, antioxidant and membrane-stabilizing effects, except iron preparations, and at the same time exert a regulatory effect on the metabolism of physiologically active compounds and improve the functional condition of patients.

The aim. The aim of this study was to identify and compare the effect of oral ferrotherapy and combined use of ferrotherapy with L-carnitine on exercise tolerance (ET) of patients with CHF with reduced ejection fraction of left ventricle (LVEF) with concomitant iron deficiency anemia (IDA) was determined and compared.

Materials and methods. The study includes 62 patients with CHF with reduced LVEF FC II-III according to NYHA with IDA. Patients with hypertensive and ischemic etiology of HF took part in the study. Among them, 45 (72.6 \%) were men and 17 (27.4 \%) were women aged $70.0 \pm 0.9$ years. Two study groups were formed: in addition to the standard therapy, the patients in the 1 st group ( $\mathrm{n}=32$ ) were prescribed oral ferrous sulfate in a dose of $320 \mathrm{mg}$, equivalent to $100 \mathrm{mg}$ of bivalent iron and $60 \mathrm{mg}$ of ascorbic acid 2 tablets per day for 6 months; the patients in the 2nd group $(n=30)$ received the standard therapy of CHF and not only iron, but also L-carnitine.

Results and discussion. The use of two variants of ferrocorrection as an application to the standard treatment of CHF among the total number of studied patients with IDA indicates the sufficient effect both to eliminate the signs of anemia and to eliminate ID. The analysis of the dynamics of the passed test distance with a 6-minute walk in 32 patients with IDA on the background of standard treatment and additional ferrotherapy after 6 months showed an increase of the actual distance by $8.9 \%$ (from 249.4 to $272.3 \mathrm{~m}, \mathrm{p}<0.0001$ ). The analysis of changes in the value of travelled distance among patients with IDA who received combined 6-month ferrotherapy with L-carnitine also revealed a significant positive trend. In addition, the value obtained was significantly higher compared to the results of patients with only additional ferrotherapy, an increase of $19.4 \%$ (from 259.5 to $304.5 \mathrm{~m}, \mathrm{p}<0.0001$ ).

Conclusions. The use of metabolic therapy with oral ferrotherapy is accompanied by a greater increase in ET, which is reflected in a significantly longer test distance with a 6-minute walk and greater frequency of decrease of FC of HF among patients, compared with using only iron sulfate ferrocorrection.
\end{abstract}

Keywords: chronic heart failure, iron deficiency anemia, indices of iron metabolism.

DOI: $10.21303 / 2504-5679.2019 .001085$

\section{Introduction}

Today, the question of the importance of iron deficiency (ID) as a new therapeutic goal for reducing symptoms, quality of life (QOL) and prognosis of patients with chronic heart failure $(\mathrm{CHF})$ is rather acute $[1,2]$.

The prevalence of anemia as a manifest form of ID of patients with HF reaches about $30 \%$ in outpatient and about $50 \%$ in hospitalized patients [3]. According to the above numbers, it can be concluded that ID is a very common comorbidity of CHF, which is known to be independent of sex, race and left ventricular (LV) ejection fraction (EF) (LVEF) [3], but is related to age [4] and 
increase in functional class (FC) of chronic heart failure according to NYHA classification - at FC III to $33 \%$ and at FC IV to $80 \%[5,6]$.

Numerous studies aimed at identifying the causes and mechanisms of occurrence of ID with and without anemic syndrome during $\mathrm{CHF}$, have found that proinflammatory activity and anemia of chronic disease (ACD) [7] are the most common causes of anemia of patients with CHF [1]. In other words, ID during CHF is more often functional. Whereas, manifest absolute ID -IDA among the total number of anemic patients with $\mathrm{CHF}$ is less common [1]. However, regardless of the variant of iron metabolism disorder that underlies the development of anemia, patients with ID present a significant problem for practical health care since the anemia syndrome during CHF is associated with an increase in mortality and the frequency of hospitalizations of patients $[3,8,9]$. In addition, ID independently of anemia contributes to the development of skeletal muscle dysfunction, which in turn causes a decrease in exercise tolerance (ET) of patients and serves as an independent factor in reducing the QL of patients $[10,11]$. When anemia occurs, there are compensatory hemodynamic mechanisms that lead to the progression of HF and consequently further reduce ET and clinical condition of patients [5].

At the same time, it is known that effective correction of anemic syndrome of patients with CHF improves the condition and clinical prognosis [5]. According to modern approaches to correction of IDA of patients with CHF the most often are used peroral and parenteral ferrocorrection.

However, the modern pharmacological strategy for the treatment of IDA of patients with CHF must take into account, without fail, the nature of metabolic disorders that occur simultaneously with iron metabolism disorders. The pathogenetic justification is the use of agents that have antihypoxic, antioxidant and membrane-stabilizing effects, except iron preparations, and at the same time exert a regulatory effect on the metabolism of physiologically active compounds and improve the functional condition of patients.

The aim of this study was to identify and compare the effect of oral ferrotherapy and combined use of ferrotherapy with L-carnitine on exercise tolerance of patients with chronic heart failure with reduced ejection fraction of left ventricle with concomitant iron deficiency anemia.

\section{Materials and methods}

The study includes 62 patients with CHF with reduced LVEF FC II-III according to NYHA with IDA. Patients with hypertensive and ischemic etiology of HF took part in the study. Among them, $45(72.6 \%)$ were men and $17(27.4 \%)$ were women aged $70.0 \pm 0.9$ years. All patients were hospitalized in the therapeutic departments of the Vinnytsia Regional Clinical Hospital of War Veterans in the period from 2013 to 2017.

The study was conducted with the consent of patients in accordance with the basic bioethical standards of the World Health Association Declaration on Ethical Principles for Conducting Scientific and Medical Research as amended (2008), Universal Declaration of Bioethics and Human Rights (1997), Council of Europe Convention on Human Rights and Biomedicine (1997). Patients' consent, together with other documents related to the study, were approved at the meeting of the Academic Council of National Pirogov Memorial Medical University, Vinnytsya (excerpt from protocol No. 4 of 26.04.2016)

During the selection phase, all patients underwent general clinical examination with a compulsory laboratory assessment of hemoglobin $(\mathrm{Hb})$, red blood cells (Rbc), color index (CI), hematocrit, Rbc indices: $\mathrm{MCV}, \mathrm{MCH}, \mathrm{MCHC}$ and levels of serum iron (SI), ferritin, total iron-binding capacity of serum (TIBC) and transferrin saturation (TS).

For the diagnosis of IDA, the following criteria were used:

1) a decrease Hgb level in men $<130 \mathrm{~g} / 1$ and in women $<120 \mathrm{~g} / \mathrm{l}$;

2) SI in women $<11.5 \mu \mathrm{mol} / 1$ and in men $<13.0 \mu \mathrm{mol} / 1$;

3) ferritin level $<100 \mathrm{ng} / \mathrm{ml}$.

Anemia of mild degree was determined in the case of Hgb values - 110-119 g/1 for women and $110-129 \mathrm{~g} / 1$ for men, moderate - within 109-80 g/l and severe $-<80 \mathrm{~g} / \mathrm{l}$, as for women and for men (WHO, 2011). Only patients with mild and moderate anemia were included in the study.

To determine the changes of effort tolerance (ET) in patients during treatment, the dynamics analysis of the covered six-minute walk test distance was conducted. 
According to the study design, all patients received standard therapy indicated by modern ESC recommendations, taking into account ischemic and hypertensive etiology of CHF and comorbid conditions, such as atrial fibrillation.

In order to avoid the possible impact of standard treatment on the results of ferrotherapy, standard drug regimens were prescribed. Drug dosages were selected individually, taking into account the patients' clinical condition.

Two study groups were formed: in addition to the standard therapy, the patients in the 1st group ( $\mathrm{n}=32$ ) were prescribed oral ferrous sulfate in a dose of $320 \mathrm{mg}$, equivalent to $100 \mathrm{mg}$ of bivalent iron and $60 \mathrm{mg}$ of ascorbic acid 2 tablets per day for 6 months; the patients in the 2nd group $(n=30)$ received the standard therapy of CHF and not only iron, but also L-carnitine.

The groups of patients were compared by gender, age, main clinical characteristics and treatment (Table 1).

Table 1

Clinical characteristics of patients with CHF with reduced EF of LV depending on additional treatment

\begin{tabular}{|c|c|c|}
\hline Characteristics & $\begin{array}{l}\text { 6-month ferrotherapy } \\
\qquad \mathrm{n}=32\end{array}$ & $\begin{array}{l}\text { 6-month ferrotherapy with L-carnitine } \\
\qquad n=30\end{array}$ \\
\hline Age, years $(\mathbf{M} \pm \sigma)$ & $70.9 \pm 1,2$ & $69.2 \pm 1.4$ \\
\hline \multicolumn{3}{|l|}{ Sex, \%: } \\
\hline Men & 62.5 & 75 \\
\hline Women & 37.5 & 25 \\
\hline Angina pectoris, $\%$ & 46.9 & 53.3 \\
\hline Myocardial infarction, \% & 31.3 & 33.3 \\
\hline Diabetes, $\%$ & 28.1 & 36.7 \\
\hline \multicolumn{3}{|l|}{ FC CHF, \% } \\
\hline II FC & 18.8 & 26.7 \\
\hline III FC & 81.2 & 73.3 \\
\hline \multicolumn{3}{|c|}{$\begin{array}{l}\text { Hematological parameters, median } \\
\text { (lower, upper quartile): }\end{array}$} \\
\hline $\mathrm{Hb}, \mathrm{g} / \mathrm{l}$ & $106.5(96.5 ; 116.5)$ & $108(97 ; 116)$ \\
\hline $\mathrm{Rbc}, \times 10^{12} / 1$ & $4.25(3.9 ; 4.48)$ & $3.9(3.87 ; 4.45)$ \\
\hline CI & $0.77(0.70 ; 0.84)$ & $0.80(0.7 ; .82)$ \\
\hline Het, $1 / 1$ & $0.32(0.32 ; 0.36)$ & $0.32(0.31 ; 0.35)$ \\
\hline $\mathrm{MCV}, \mathrm{fl}$ & $80.5(77.1 ; 81.9)$ & $81.9(79.5 ; 83.3)$ \\
\hline $\mathrm{MCH}, \mathrm{pg}$ & $25.6(23.2 ; 28)$ & $26.4(24.5 ; 27.2)$ \\
\hline $\mathrm{MCHC}, \mathrm{g} / 1$ & $318(308.7 ; 327.9)$ & $322.7(312.5 ; 340.6)$ \\
\hline SI, umol/1 & $7,9(6,2 ; 10,3)$ & $9,55(6,4 ; 11,2)$ \\
\hline Ferritin, $\boldsymbol{\mu} \mathbf{g} / 1$ & $63(41 ; 82.5)$ & $43.5(31 ; 76)$ \\
\hline $\mathrm{TS}, \%$ & $11.1(8 ; 13.3)$ & $12.8(8 ; 15.2)$ \\
\hline TIBC, umol/1 & $77(67.5 ; 87.7)$ & $74.1(68.2 ; 86.5)$ \\
\hline \multicolumn{3}{|c|}{ Medication/Group of medications, $\%$ : } \\
\hline ACE inhibitors & 66.1 & 53.3 \\
\hline ARBs & 33.9 & 30 \\
\hline$\beta$-blockers & 91.9 & 88.3 \\
\hline Spironolactone & 95.2 & 98.3 \\
\hline Digoxin & 11.3 & 8.3 \\
\hline Nitrates & 37.1 & 20 \\
\hline Amlodipine & 43.5 & 40 \\
\hline TD/TLD & 43.5 & 43.3 \\
\hline Warfarin & 11.3 & 11.7 \\
\hline ASA & 88.7 & 88.3 \\
\hline Atorvastatin & 100 & 100 \\
\hline Amiodarone & 12.9 & 13.3 \\
\hline
\end{tabular}

Note: ACE inhibitors - angiotensin converting enzyme inhibitors, ARBs - angiotensin II receptor blockers, $\beta$-blockers - beta-adrenergic blocking agents, ASA - acetylsalicylic acid, TD/TPD - thiazide and thiazide-like diuretics 
Statistical processing of the obtained results was performed using the software package Microsoft Office Excel and Statistica. Due to abnormal distribution of data, the obtained measurements are presented as a median (lower, upper quartile). The statistical significance of the difference in the measured parameters among the groups was calculated according to Kruskal-Wallis ANOVA \& Median test for all groups criterion, and the difference between the results of 6-month treatment and the output values was calculated according to Wilcoxon matched pairs test criterion. The difference in the frequency of signs (\%) was calculated by the $\chi^{2}$ criterion. The difference was considered reliable at $\mathrm{p}<0.05$.

\section{Results}

The use of two variants of ferrocorrection as an application to the standard treatment of CHF among the total number of studied patients with IDA indicates the sufficient effect both to eliminate the signs of anemia and to eliminate ID. A comparative analysis of the clinical and hematological effectiveness of 6-month oral ferrotherapy with iron sulfate and the effectiveness of combined ferro- and metabolic therapy showed no difference since the intergroup distribution of patients with different hematological evolution in the two treatment groups did not differ $(\mathrm{p}=0.83)$

(Table 2). In both groups, the percentage of patients with eliminated IDA was predominant.

Table 2

Distribution of patients with CHF with reduced LVEF depending on hematological evolution after treatment (in \%)

\begin{tabular}{ccc}
\hline Clinical-hematological characteristics & $\begin{array}{c}\text { 6-month ferrotherapy } \\
\mathbf{n = 3 2}\end{array}$ & $\begin{array}{c}\text { 6-month ferrotherapy with L-carnitine } \\
\mathbf{n}=\mathbf{3 0}\end{array}$ \\
\hline IDA & 9.4 & 10 \\
ACD and IDA & 3.1 & 0 \\
Without ID & 68.8 & 76.7 \\
Functional ID & 3.1 & 3.3 \\
Absolute ID & 15.6 & 10
\end{tabular}

Note: The cross-group difference in \% of different variants of hematological evolution between the two treatment groups which was calculated by $\chi 2$ criterion, is unreliable $(p=0.83)$

Comparison of the studied laboratory parameters of patients with IDA after 6 months with different options for additional treatment revealed no difference in the increase in hematological parameters, except for the levels of Hct, which were higher for patients who received additional L-carnitine. In addition, in patients receiving metabolic therapy, there was a tendency to a greater increase in $\mathrm{Hgb}$ and $\mathrm{Rbc}$ (Table 3).

Table 3

Comparison of hematological parameters of patients with CHF with reduced LVEF with IDA after treatment, median (lower, upper quartile)

\begin{tabular}{ccccccc}
\hline \multirow{2}{*}{ Parameters } & \multicolumn{3}{c}{$\begin{array}{c}\text { 6-month ferrotherapy } \\
\mathbf{n}=\mathbf{3 2}\end{array}$} & \multicolumn{3}{c}{$\mathbf{6}$-month ferrotherapy with L-carnitine } \\
& Initial value & $\mathbf{6}^{\text {th }}$ month & Dynamics, $\mathbf{0}$ & Initial value & $\mathbf{6}^{\text {th }}$ month & Dynamics, \% \\
\cline { 2 - 7 } & $\mathbf{2}$ & $\mathbf{3}$ & $\mathbf{4}$ & $\mathbf{5}$ & $\mathbf{6}$ & $\mathbf{7}$ \\
\hline $\mathbf{1}$ & 106.5 & 138 & +28.6 & 108 & 141 & +31.6 \\
$\mathrm{Hb}, \mathrm{g} / 1$ & $(96.5 ; 116.5)$ & $(131.5 ; 147)^{* *}$ & $(+25.3 ;+34.5)$ & $(97 ; 116)$ & $(134 ; 147)^{* *}$ & $(+24.8 ;+36.8)$ \\
& 4.25 & 4.6 & +8.9 & 3.9 & 4.6 & +11.5 \\
$\mathrm{Rbc}, \times 10^{12} / 1$ & $(3.9 ; 4.48)$ & $(435 ; 4.9)^{* *}$ & $(+3.9 ;+14.6)$ & $(3.87 ; 4.45)$ & $(4.3 ; 4.9)^{* *}$ & $(+5.6 ;+15.6)$ \\
& 0.77 & 0.88 & +17.6 & 0.80 & 0.91 & +15.9 \\
$\mathrm{CI}$ & $(0.70 ; 0.84)$ & $(0.86 ; 0.94)^{* *}$ & $(+8 ;+22)$ & $(0.7 ; .82)$ & $(0.89 ; 0.95)^{* *}$ & $(+8.3 ;+22.2)$ \\
& 0.32 & 0.37 & +12.5 & 0.32 & 0.39 & +19.6 \\
Hct, $1 / 1$ & $(0.32 ; 0.36)$ & $(0.35 ; 0.41)^{* *}$ & $(+9.2 ;+21.5)$ & $(0.31 ; 0.35)$ & $(0.37 ; 0.4)^{* *}$ & $(+14.1 ;+25) \#$
\end{tabular}


Continuation of Table 3

\begin{tabular}{|c|c|c|c|c|c|c|}
\hline 1 & 2 & 3 & 4 & 5 & 6 & 7 \\
\hline $\mathrm{MCV}, \mathrm{fl}$ & $\begin{array}{c}80.5 \\
(77.1 ; 81.9)\end{array}$ & $\begin{array}{c}83.8 \\
(77.2 ; 86.8)^{*}\end{array}$ & $\begin{array}{c}+6 \\
(-1.5 ;+10.7)\end{array}$ & $\begin{array}{c}81.9 \\
(79.5 ; 83.3)\end{array}$ & $\begin{array}{c}85.8 \\
(80 ; 90)^{*}\end{array}$ & $\begin{array}{c}+6.7 \\
(+0.4 ;+10.8)\end{array}$ \\
\hline $\mathrm{MCH}, \mathrm{pg}$ & $\begin{array}{c}25.6 \\
(23.2 ; 28)\end{array}$ & $\begin{array}{c}29.3 \\
(28.4 ; 31.1)^{* *}\end{array}$ & $\begin{array}{c}+17.6 \\
(+8 ;+28)\end{array}$ & $\begin{array}{c}26.4 \\
(24.5 ; 27.2)\end{array}$ & $\begin{array}{c}30.3 \\
(29.5 ; 31.4)^{* *}\end{array}$ & $\begin{array}{c}+15.9 \\
(+8.3 ;+22.2)\end{array}$ \\
\hline $\mathrm{MCHC}, \mathrm{g} / 1$ & $\begin{array}{c}318 \\
(308.7 ; 327.9)\end{array}$ & $\begin{array}{c}358 \\
(339.2 ; 384)^{* *}\end{array}$ & $\begin{array}{c}+12.6 \\
(+7.5 ;+19.6)\end{array}$ & $\begin{array}{c}322.7 \\
(312.5 ; 340.6)\end{array}$ & $\begin{array}{c}351.9 \\
(343.6 ; 371)^{* *}\end{array}$ & $\begin{array}{c}+9.4 \\
(+0.80 ;+14.8)\end{array}$ \\
\hline SI, umol/1 & $\begin{array}{c}7.9 \\
(6.2 ; 10.3)\end{array}$ & $\begin{array}{c}15.3 \\
(12.9 ; 18)^{* *}\end{array}$ & $\begin{array}{c}+82.6 \\
(+63.6 ; \text { an } \\
\text { increase of } 2.1 \\
\text { times })\end{array}$ & $\begin{array}{c}9.55 \\
(6.4 ; 11.2)\end{array}$ & $\begin{array}{c}16 \\
(13.7 ; 18.4)^{* *}\end{array}$ & $\begin{array}{c}+87.2 \\
(+62.8 ; \text { an } \\
\text { increase of } 2.1 \\
\text { times })\end{array}$ \\
\hline Ferritin, $\mu \mathrm{g} / 1$ & $\begin{array}{c}63 \\
(41 ; 82.5)\end{array}$ & $\begin{array}{c}133.5 \\
(99 ; 179)^{* *}\end{array}$ & $\begin{array}{c}\text { an increase } \\
\text { of } 2.3 \text { times } \\
\text { (+90.4; of } 3.2 \\
\text { times) }\end{array}$ & $\begin{array}{c}43.5 \\
(31 ; 76)\end{array}$ & $\begin{array}{c}119 \\
(104 ; 158)^{* *}\end{array}$ & $\begin{array}{c}\text { an increase of } \\
2.5 \text { times } \\
\text { (of } 2 ; \text { of } 3.2 \\
\text { times) }\end{array}$ \\
\hline TS, $\%$ & $\begin{array}{c}11.1 \\
(8 ; 13.3)\end{array}$ & $\begin{array}{c}23.7 \\
(17.7 ; 30)^{* *}\end{array}$ & $\begin{array}{l}\text { an increase of } \\
2.2 \text { times }(+77.8 ; \\
\text { of } 2.8 \text { times) }\end{array}$ & $\begin{array}{c}12.8 \\
(8 ; 15.2)\end{array}$ & $\begin{array}{c}27 \\
(20.4 ; 32.3)^{* *}\end{array}$ & $\begin{array}{l}\text { an increase of } \\
2.2 \text { times ( }+76.8 \text {; } \\
\text { of } 2.8 \text { times) }\end{array}$ \\
\hline TIBC, umol/1 & $\begin{array}{c}77 \\
(67.5 ; 87.7)\end{array}$ & $\begin{array}{c}65.5 \\
(59 ; 74.5)^{* *}\end{array}$ & $\begin{array}{c}-13.6 \\
(-17.7 ;-7.4)\end{array}$ & $\begin{array}{c}74.1 \\
(68.2 ; 86.5)\end{array}$ & $\begin{array}{c}64.1 \\
(57 ; 69)^{* *}\end{array}$ & $\begin{array}{c}-17.8 \\
(-22.5 ;-7.47)\end{array}$ \\
\hline
\end{tabular}

Note: ${ }^{*}-p<0.01$ when compared with initial values; ${ }^{*}-p<0.0001$ when compared with initial values; \#-p<0.05 when comparing values of different observation groups after treatment

The analysis of the dynamics of the passed test distance with a 6-minute walk in 32 patients with IDA on the background of standard treatment and additional ferrotherapy after 6 months showed an increase of the actual distance by $8.9 \%$ (from 249.4 to $272.3 \mathrm{~m}, \mathrm{p}<0.0001$ ) (Fig. 1). The analysis of changes in the value of travelled distance among patients with IDA who received combined 6-month ferrotherapy with L-carnitine also revealed a significant positive trend. In addition, the value obtained was significantly higher compared to the results of patients with only additional ferrotherapy, an increase of $19.4 \%$ (from 259.5 to $304.5 \mathrm{~m}, \mathrm{p}<0.0001$ ).

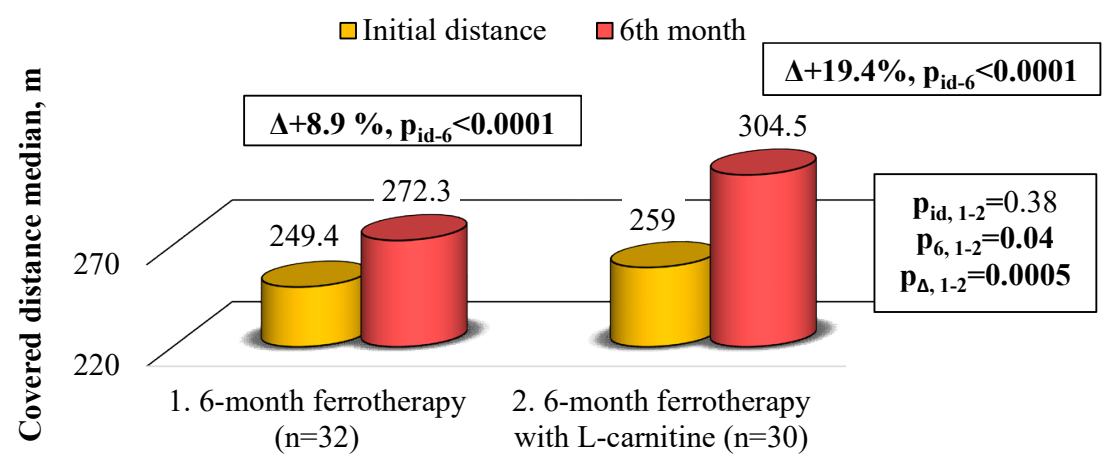

Fig. 1. The dynamics of the covered six-minute walk test distance in patients with CHF with reduced LVEF and IDA on the background of the treatment: $p_{\text {id- } 6}$ - reliability of differences between initial distance and post-treatment distance; $\mathrm{p}_{\mathrm{id}, 1-2}$ - reliability of initial distance differences between two treatment groups; $\mathrm{p}_{6,1-2}$ - reliability of distance differences after 6 months of observations between two treatment groups; $p_{\Delta, 1-2}$ - reliability of changes difference between two treatment groups

Analysis of the distribution of CHF FC by NYHA among all patients with IDA showed a significant positive dynamics and reduction of FC by 1 class during treatment compared to the initial distribution in $14(22.6 \%)$ patients $(\mathrm{p}<0.0001)$.

Evaluation of changes in FC dynamics on the background of different treatment revealed a tendency $(p<0.08)$ to increase the number of cases of reduction of FC CHF by NYHA in pa- 
tients treated with iron and L-carnitine, compared with patients treated only with ferrotherapy (26.7\% vs. $18.8 \%$, respectively).

\section{Discussion}

Taking into account the disadvantages of oral ferrocorrection - slow absorption in the gastrointestinal tract and its decreased level in conditions of minimal possible inflammation in case of CHF and due to blood congestion, in order to improve patients' physical functioning and general condition, oral ferrotherapy in patients with CHF and concomitant IDA was prolonged in our study. In our study, the obtained data show that hematological indices dynamics in patients who received 6-month ferrotherapy as markers of ferrocorrection efficacy, demonstrated an increase in all parameters and corresponding normalization of iron metabolism indices and to eliminate the signs of anemia in most cases. Thus, it can be argued that ferrotherapy with iron sulfate at the stage of iron deficiency anemia in patients with heart failure with reduced left ventricular ejection fraction for a period of 6 months is effective. In addition, positive hematologic dynamics was accompanied by a major improvement in effort tolerance indices. Because ID, even in the absence of anemia, is a factor of a decrease of physical capacity and quality of life [12] and medicated correction of ID in case of CHF brings positive changes in patients' condition.

However, long-term oral ferrotherapy can only be used in patients with absolute ID. IDA is caused by the multifactorial depletion of iron in the body and the main way of its correction is the use of oral or intravenous iron. Hepcidin function to block intestinal iron absorption and iron release from the mononuclear-phagocyte system, which occur due to activation of proinflammatory cytokines, have an impact on the development of ACD as a functional ID. Therefore, the use of oral iron supplements in this type of ID is not effective, and moreover, dangerous due to possible occurrence of hemosiderosis [1]. Therefore, for the effective treatment of patients with CHF and iron deficiency with anemic syndrome, it is necessary to differentiate the variant of iron metabolism by biochemical parameters.

L-carnitine is a vitamin-like and modified amino acid that plays an important role in supporting the body's metabolic activities. There is growing evidence that high concentrations of L-carnitine provide beneficial effects in various diseases such as coronary artery disease, congestive heart failure, peripheral vascular diseases, type 2 diabetes, dyslipidemia, and hypertension [13-16]. However, as a treatment of heart failure, L-carnitine has not been recommended in patients with current or prior symptoms of heart failure with reduced ejection fraction and heart failure with preserved ejection fraction in the American guideline [17, 18]. The recommendation of nutritional supplements has not been proposed in the European guideline [19].

Our study demonstrated that despite the same hematological efficacy, oral ferrotherapy and ferrotherapy in combination with the use of L-carnitine in patients with CHF with reduced LVEF and concomitant IDA have a positive clinical efficacy in relation to the physical ability of patients. However, the use of metabolic therapy with oral ferrotherapy is accompanied by a greater increase in ET, compared with using only iron sulfate ferrocorrection.

Thus confirmed that L- carnitine represents a safe and effective adjuvant therapy which, by increasing high energy phosphate for systolic function, may have a synergistic effect with other drugs $[12,20]$. L-carnitine treatment in CHF patients may improve clinical symptoms and the physical capacity, which is particularly relevant for anemic patients. Therefore, the proposed treatment regimen may be recommended for use as additional treatment for patients with chronic heart failure with reduced left ventricular ejection fraction and concomitant iron deficiency anemia.

Limitations of the study. For patients with $\mathrm{CH}$ and iron deficiency, it is necessary to determine its type. It can be diagnosed only by determining the biochemical parameters of iron metabolism that is not routinely used. However, this is a way to help determine an effective treatment method.

Prospects for further research. Because the use of metabolic therapy with oral ferrotherapy is accompanied by a greater increase in ET compared with using only iron sulfate ferrocorrection, there is a need to identify the effect of combined use of ferrotherapy with L-carnitine on others clinical and instrumental parameters of patients with CHF with reduced LVEF. 


\section{Conclusions}

The use of oral 6-month ferrotherapy and 6-month ferrotherapy in combination with L-carnitine in the treatment of CHF with reduced EF of LV with concomitant IDA eliminated anemia in $87.5 \%$ and $90 \%$ of patients, and iron deficiency in $68.8 \%$ and $76.7 \%$, respectively. Which in turn allows us to attest to the sufficient effect of the two options for additional treatment of CHF with concomitant IDA, both to eliminate the signs of anemia and to eliminate ID.

Despite the same hematological efficacy, oral ferrotherapy and ferrotherapy in combination with the use of L-carnitine as adjunct options to the standard treatment of CHF with reduced LVEF with concomitant IDA have a positive but different clinical efficacy in relation to the physical ability of patients.

The use of metabolic therapy with oral ferrotherapy is accompanied by a greater increase in ET, which is reflected in a significantly longer test distance with a 6-minute walk and greater frequency of decrease of FC of HF among patients, compared with using only iron sulfate ferrocorrection.

\section{References}

[1] Voronkov, L. G. (2015) Anemiya u pacienta s HSN: kak ocenivat i kak lechit? Sertseva nedostatnist, 2, 5-15.

[2] Mamas, M. A., Sperrin, M., Watson, M. C., Coutts, A., Wilde, K., Burton, C. et. al. (2017). Do patients have worse outcomes in heart failure than in cancer? A primary care-based cohort study with 10-year follow-up in Scotland. European Journal of Heart Failure, 19 (9), 1095-1104. doi: http://doi.org/10.1002/ejhf.822

[3] Anand, I. S., Gupta, P. (2018). Anemia and Iron Deficiency in Heart Failure. Circulation, 138 (1), 80-98. doi: http://doi.org/ 10.1161/circulationaha.118.030099

[4] Goodnough, L. T., Schrier, S. L. (2014). Evaluation and management of anemia in the elderly. American Journal of Hematology, 89 (1), 88-96. doi: http://doi.org/10.1002/ajh.23598

[5] Ivanov, V. P., Kolesnyk, M. O., Kolesnyk, O. M., Ivanova, Y. I. (2018). Anemia from the perspective of the problem of chronic heart failure: pathogenesis and laboratory diagnosis. Acta Medica Leopoliensia, 24 (2), 69-76. doi: http://doi.org/10.25040/ aml2018.02.069

[6] Stuklov, N. I. (2017). Iron deficiency and anemia in patients with chronic heart failure. Rational Pharmacotherapy in Cardiology, 13 (5), 651-660. doi: http://doi.org/10.20996/1819-6446-2017-13-5-651-660

[7] Weiss, G. (2009). Iron metabolism in the anemia of chronic disease. Biochimica et Biophysica Acta (BBA) - General Subjects, 1790 (7), 682-693. doi: http://doi.org/10.1016/j.bbagen.2008.08.006

[8] Anand, I. S. (2008). Anemia and Chronic Heart Failure. Journal of the American College of Cardiology, 52 (7), $501-511$. doi: http://doi.org/10.1016/j.jacc.2008.04.044

[9] Ivanov, V. P., Kolesnyk, M. O. (2019). Comparative characteristics of quality of life indicators in patients with chronic heart failure with reduced left ventricular ejection fraction depending on iron deficiency type. Eastern Ukrainian Medical Journal, 7 (3), 246-256. doi: http://doi.org/10.21272/eumj.2019;7(3):246-256

[10] Tang, Y.-D., Katz, S. D. (2008). The prevalence of anemia in chronic heart failure and its impact on the clinical outcomes. Heart Failure Reviews, 13 (4), 387-392. doi: http://doi.org/10.1007/s10741-008-9089-7

[11] Duygu, K., Kadri, M. G. (2016). Iron deficiency and its treatment in heart failure: indications and effect on prognosis. E-Journal of Cardiology Practice, 14 (30). Available at: https://www.escardio.org/Journals/E-Journal-of-Cardiology-Practice/Volume-14/Iron-deficiency-and-its-treatment-in-heart-failure-indications-and-effect-on-prognosis

[12] Comín-Colet, J., Enjuanes, C., González, G., Torrens, A., Cladellas, M., Meroño, O. et. al. (2013). Iron deficiency is a key determinant of health-related quality of life in patients with chronic heart failure regardless of anaemia status. European Journal of Heart Failure, 15 (10), 1164-1172. doi: http://doi.org/10.1093/eurjhf/hft083

[13] Song, X., Qu, H., Yang, Z., Rong, J., Cai, W., Zhou, H. (2017). Efficacy and Safety of L-Carnitine Treatment for Chronic Heart Failure: A Meta-Analysis of Randomized Controlled Trials. BioMed Research International, 2017, 1-11. doi: http://doi.org/ $10.1155 / 2017 / 6274854$

[14] Anon Acetyl-L-carnitine (2010). Altern Med Rev, 15 (1), $76-83$.

[15] Ferrari, R., Merli, E., Cicchitelli, G., Mele, D., Fucili, A., Ceconi, C. (2004). Therapeutic Effects of 1-Carnitine and Propionyl-1-carnitine on Cardiovascular Diseases: A Review. Annals of the New York Academy of Sciences, 1033 (1), 79-91. doi: http://doi.org/10.1196/annals.1320.007

[16] Marcovina, S. M., Sirtori, C., Peracino, A., Gheorghiade, M., Borum, P., Remuzzi, G., Ardehali, H. (2013). Translating the basic knowledge of mitochondrial functions to metabolic therapy: role of L-carnitine. Translational Research, 161 (2), $73-84$. doi: http://doi.org/10.1016/j.trs1.2012.10.006 
[17] Yancy, C. W., Jessup, M., Bozkurt, B., Butler, J., Casey, D. E., Drazner, M. H. et. al. (2013). ACCF/AHA guideline for the management of heart failure: executive summary: a report of the American college of cardiology foundation. American Heart Association task force on practice guidelines. Circulation, 128 (16), 1810-1852. doi: http://doi.org/10.1161/cir.0b013e31829e8807

[18] Mant, J., Al-Mohammad, A., Swain, S., Laramée, P. (2011). Management of Chronic Heart Failure in Adults: Synopsis of the National Institute for Health and Clinical Excellence Guideline. Annals of Internal Medicine, 155 (4), 252-259. doi: http:// doi.org/10.7326/0003-4819-155-4-201108160-00009

[19] Špinar, J., Hradec, J., Špinarová, L., Vítovec, J. (2016). Summary of the 2016 ESC Guidelines on the diagnosis and treatment of acute and chronic heart failure. Prepared by the Czech Society of Cardiology. Cor et Vasa, 58 (5), e530-e568. doi: http:// doi.org/10.1016/j.crvasa.2016.09.004

[20] Andreozzi, G. M., Leone, A., Laudani, R., Martin, R., Deinit, G., Cataldi, V. (2008). Levo-Propionyl-Carnitine Improves the Effectiveness of Supervised Physical Training on the Absolute Claudication Distance in Patients With Intermittent Claudication. Angiology, 59 (1), 84-89. doi: http://doi.org/10.1177/0003319707304567

\title{
EVALUATION OF PAIN SYNDROME AND EFFICIENCY OF PAIN MANAGEMENT IN LUMBAR SPINE SURGERY
}

\author{
Mykola Lyzohub \\ SI "Sytenko Institute of Spine and Joint Pathology NAMS of Ukraine" \\ 80 Pushkinskaja str., Kharkiv, Ukraine, 61024 \\ nlizogub@gmail.com \\ Marine Georgiyants ${ }^{1}$ \\ mgeor@i.ua \\ Kseniia Lyzohub ${ }^{1}$ \\ kslizogub@gmail.com \\ ${ }^{1}$ Kharkiv Medical Academy of Postgraduate Education \\ 58 Amosova str., Kharkiv, Ukraine, 61176
}

\begin{abstract}
Multimodal analgesia for lumbar spine surgery is still a controversial problem, because of possible fusion problems, significant neuropathic component of pain, and influence of anesthesia type. Aim of the study was to assess the efficacy of pain management after lumbar spine surgery considering characteristics of pain, type of anesthesia and analgesic regimen.

Material and methods. 254 ASA I-II patients with degenerative lumbar spine disease were enrolled into prospective study. Patients were operated either under spinal anesthesia (SA) or total intravenous anesthesia (TIVA). In postoperative period patients got either standard pain management (SPM - paracetamol \pm morphine) or multimodal analgesia (MMA - paracetamol + parecoxib + + pregabalin \pm morphine).

Results. We revealed neuropathic pain in $53.9 \%$ of patients, who were elected for lumbar spine surgery. VAS pain score in patients with neuropathic pain was higher, than in patients with nociceptive pain. Total intravenous anesthesia was associated with greater opioid consumption during the first postoperative day. Multimodal analgesia based on paracetamol, parecoxib and pregabalin allowed to decrease requirements for opioids, postoperative nausea and dizziness. Pregabalin used for evening premedication had equipotential anxiolytic effect as phenazepam without postoperative cognitive disturbances.

Conclusions. Multimodal analgesia is opioid-sparing technique that allows to decrease complications. Spinal anesthesia is associated to a decreased opioid consumption in the 1st postoperative day.

Keywords: lumbar spine surgery, anesthesia, multimodal analgesia.
\end{abstract}

